\title{
Dez anos de parâmetros curriculares nacionais: a prática da Educação Física na visão dos seus autores
}

\author{
Lílian Cristina Gramorelli* \\ Marcos Garcia Neira**
}

\begin{abstract}
Resumo: O estudo averiguou possíveis apropriações dos pressupostos teórico-metodológicos contidos nos Parâmetros Curriculares Nacionais de Educação Física pelos professores atuantes nos anos finais do Ensino Fundamental. A análise da publicação oficial permitiu identificar encaminhamentos didáticos diferenciados com relação àqueles que compunham a tradição da área. A partir desses elementos e recorrendo ao método projetivo, desenvolveu-se uma entrevista com grupo focal. Os dados obtidos apontam percepções docentes que reconfiguram a prática educativa. A interpretação dos resultados permitiu constatar que as concepções dos professores se aproximam das proposições contidas no documento oficial, mesmo que nenhuma alusão Ihe tenha sido feita.

Palavras-chave: Educação Física. Ensino fundamental. Currículo. Aprendizagem.
\end{abstract}

\section{A problemática}

E tu para que queres um barco, pode-se saber, foi o que o rei de facto perguntou quando finalmente se deu por instalado, com sofrível comodidade, na cadeira da mulher da limpeza. Para ir à procura da ilha desconhecida, respondeu o homem. Que ilha desconhecida, perguntou o rei disfarçando o riso, como se tivesse na sua frente um louco varrido, dos que têm a mania de navegações, a quem não seria bom contrariar logo de entrada. A ilha desconhecida, repetiu o homem. Disparate, já não há ilhas desconhecidas. Quem foi que te disse, rei, que não há ilhas desconhecidas. Estão todas nos mapas. (SARAMAGO, 1998, p. 16-17).

\footnotetext{
" Mestre em Educação pela USP. Grupo de Pesquisas em Educação Física Escolar da FEUSP. São Paulo, SP, Brasil. E-mail: ligramorelli@ig.com.br

"Doutor em Educação pela USP. Professor da Faculdade de Educação da USP. São Paulo, SP, Brasil. E-mail: mgneira@usp.br
} 
O presente artigo é fruto de uma investigação científica cuja intenção foi verificar em que medida as proposições teórico-metodológicas contidas nos Parâmetros Curriculares Nacionais (PCNs) de Educação Física foram incorporadas pelos professores em atuação nos anos finais do Ensino Fundamental, considerando o período basilar de dez anos da publicação do documento oficial.

Partiu-se do pressuposto que o movimento de reorientação curricular empreendido a partir da Lei de Diretrizes e Bases da Educação Nacional (9.394/96) e consolidado com as Diretrizes Curriculares Nacionais do Ensino Fundamental, culminou com a publicação dos PCNs. Essa ação foi importante, na medida em que as reflexões acerca das práticas educativas sinalizavam a necessidade de um novo olhar sobre o processo educativo, partindo de um pressuposto que a educação escolar deveria privilegiar as aprendizagens.

Diversos estudos históricos amplamente divulgados denunciam a correspondência entre Educação Física escolar e melhoria da aptidão física e esportiva, mediante intervenções pautadas nos aspectos motores desprovidas de reflexão, tanto por parte de quem ensinava como de quem aprendia. Até o início dos anos 1990, segundo Lima e Gramorelli (2007), pairava entre os educadores atuantes na área o consenso de que mudanças nas concepções que norteavam a ação didática do componente eram necessárias, pois se verificava que o ensino focado somente no desenvolvimento dos aspectos físicos não mais atendia aos pressupostos de uma sociedade plural e democrática. Simultaneamente, a ampliação da discussão teórica com o olhar voltado para as aprendizagens dos alunos, promovida pelos setores acadêmicos, propiciou uma leitura mais acurada sobre a prática pedagógica em vigor, desencadeando um novo olhar que permitia ver e enxergar os aspectos anteriormente velados.

Dentre vários textos que fomentaram o processo de modificações no ensino da Educação Física, os PCNs merecem destaque, pois contribuíram para fundamentar uma prática educativa diferenciada, tendo como ponto de partida a obrigatoriedade legal de inserir o componente na proposta pedagógica da escola (BRASIL, 1996).

Movimento, Porto Alegre, v. 15, n. 04, p. 107-126, outubro/dezembro de 2009. 
Nas análises de Rodrigues (2002), os PCNs apresentam alguns princípios norteadores, indicando formas de organização dos contextos educativos que se afastam das vertentes anteriores. São eles: inclusão, integração, diversidade, aprender a aprender e aprender a viver junto. Partindo daí, a autora revela uma atualização do discurso sobre a função social da Educação Física, justificando-a no contexto das novas exigências do processo de globalização para a sociedade brasileira. Para além de denunciar a ênfase dada aos aspectos prescritivos e a forma aligeirada de tratar os conceitos, a autora chama a atenção para o ecletismo presente nos PCNs quanto à definição do objeto de estudo da Educação Física, apresentado de maneira confusa e superficial, e à descrição das diferentes abordagens.

Não há uma análise crítica das diferentes abordagens de educação física existentes na atualidade e destacadas no documento, uma vez que não se apresentam as concepções de sociedade, educação e escola que as norteiam. O que existe é uma justaposição de idéias, como se estas abordagens tivessem se constituído a partir de consensos e visões (p. 138-139).

\section{O mesmo aspecto foi criticado por Caparroz (2003, p. 315):}

[...] nos PCNs de educação física do terceiro e quarto ciclos é feita menção às abordagens "psicomotora", "construtivista", "desenvolvimentista" e "críticas". Entretanto, a discussão sobre essas abordagens não ultrapassa os limites da menção. Não há discussão aprofundada do que representa política e pedagogicamente cada abordagem.

Entretanto, Neira e Nunes (2006, p. 119) possuem outra opinião. Afirmam que os PCNs encontram-se no "rastro das teorias críticas do currículo":

[...] é a preocupação com o pleno exercício da cidadania, destacado pelos critérios para decisão de conteúdos e valorização do patrimônio de conhecimentos de cada localidade expressos na proposta para a Educação Física, que nos permite classificar este desenho curricular como uma perspectiva crítica delineada nos seus objetivos para o componente.

Movimento, Porto Alegre, v. 15, n. 04, p. 107-126, outubro/dezembro de 2009. 


\section{Artigos Orifinais Lilian C. Gramorelli e Marcos G. Neira}

Os analistas debruçaram-se também sobre as formas de elaboração, apreensão e transposição da proposta para as práticas escolares. Caparroz (2003) relembra que o Ministério da Educação não convocou ou convidou a área de Educação Física para participar da construção dos PCNs e, sim, uma parcela desta restrita ao meio acadêmico e que mostrava simpatia com os pressupostos epistemológicos que sustentavam a proposta.

Quanto à divulgação dos documentos, Darido et al. (2001, p. 28), relatam:

A intenção da Secretaria de Ensino Fundamental do MEC era a de que todos os professores da rede pública do país recebessem o conjunto de documentos, o que acabou não ocorrendo. Como os documentos foram enviados para as escolas, e não para as residências dos docentes, muitos acabaram ficando sem os exemplares. O número exato de professores que receberam os documentos não foi divulgado, de toda forma, muitos foram agraciados.

Nesse contexto, eclodem os questionamentos de Caparroz (2003, p. 327):

[...] que condições o professorado tem para se apropriar e dominar criticamente o que é produzido academicamente? Como ele se relaciona com esta produção e com as orientações normativo-curriculares para construir sua autoridade e autoria docente? O professorado tem que grau de autonomia (ou é submisso) em relação a estas?

Como se nota, os professores não participaram da elaboração. Tal fato faz aumentar as chances de que, mesmo após uma década, nem todos conheçam o documento, compreendam suas intenções ou, se dele souberam, talvez pouco se recordem do seu conteúdo. A questão em tela não é perguntar aos professores de Educação Física se leram ou não os PCNs e o que entenderam, mas descobrir em que medida suas percepções acerca da prática pedagógica estão influenciadas pelos pressupostos que fundamentam o documento, já que é por meio destes que a ação educativa pode sofrer modificações.

Movimento, Porto Alegre, v. 15, n. 04, p. 107-126, outubro/dezembro de 2009. 
O processo de pesquisa, distribuído em duas etapas, compreendeu inicialmente a análise de conteúdo dos PCNs - Educação Física $-3^{\circ}$ e $4^{\circ}$ Ciclos e, na sequência, a promoção de discussões com um Grupo Focal constituído por professores atuantes nos anos finais do Ensino Fundamental, desencadeadas por meio de quatro dispositivos de evocação elaborados a partir de situações de ensino inspiradas nos pressupostos do documento.

\section{INTERPRETANDO A VOZ OFICIAL}

A análise de conteúdo do documento permitiu elucidar alguns aspectos que sinalizam mudanças para o ensino da Educação Física, quando confrontados com os referenciais e propostas para o componente, vigentes até princípios dos anos 1990. Destacam-se, devido às características inovadoras à época, os seguintes pressupostos: o princípio da inclusão, a distribuição dos conhecimentos da área em categorias e blocos de conteúdos e a forma de avaliação.

A sistematização de objetivos, conteúdos, processos de ensino e aprendizagem e avaliação têm como meta a inclusão do aluno na cultura corporal de movimento, por meio da participação e reflexão concretas e efetivas. Busca-se reverter o quadro histórico da área de seleção entre indivíduos aptos e inaptos para as práticas corporais, resultante da valorização exacerbada do desempenho e da eficiência (BRASIL, 1998, p. 19).

Pelo princípio da inclusão, infere-se uma concepção pedagógica aberta à participação de todos os alunos, independente das habilidades técnicas e/ou esportivas que possuam. Nota-se que a proposta se concentra na viabilização de condições para que o educando se insira numa parcela da cultura mais ampla, a cultura corporal. Ao participar do processo ensino-aprendizagem por meio de vivências relacionadas ao patrimônio cultural corporal, se espera que os estudantes construam conhecimentos e atrelem o pensar ao fazer.

[...] é necessário superar a ênfase na aptidão física para o rendimento padronizado, decorrente deste

Movimento, Porto Alegre, v. 15, n. 04, p. 107-126, outubro/dezembro de 2009. 


\section{Astigos Originais Lílian C. Gramorelli e Marcos G. Neira}

referencial conceitual, e caracterizar a Educação Física de forma mais abrangente, incluindo todas as dimensões do ser humano envolvidas em cada prática corporal.

Atualmente, a análise crítica e a busca de superação dessa concepção apontam a necessidade de que se considerem também as dimensões cultural, social, política e afetiva, presentes no corpo vivo, isto é, no corpo de pessoas, que interagem e se movimentam como sujeitos sociais e como cidadãos (BRASIL, 1998, p. 29). ${ }^{1}$

Percebemos que o Princípio da Inclusão que inspira a ação didática contribui para uma certa formatação na ação pedagógica dos professores e coloca em xeque a anterior valorização da aptidão física com respaldo das ciências biológicas que, por décadas, influenciou a área, sobretudo, quando se observam os textos oficiais.

Se considerarmos o posicionamento oficial, será lícito dizer que somente na última década do século XX foram traçados os caminhos para a construção de novas práticas pedagógicas na Educação Física. Práticas que privilegiam as dimensões físicas, sociais, afetivas e culturais dos estudantes, por meio da articulação dos objetivos de ensino do componente com a Proposta Pedagógica da escola. Desta maneira, a participação de todos os alunos e alunas nas aulas torna-se viável, independente de suas capacidades físicas e de seu rendimento esportivo.

Outro aspecto abordado nos PCNs que demonstra uma mudança nos paradigmas anteriores consiste na reflexão acerca do que ensinar. O documento propõe que os conteúdos em Educação Física sejam desenvolvidos nas suas dimensões conceitual, procedimental e atitudinal e aponta:

[...] uma valorização dos procedimentos sem restringi-los ao universo das habilidades motoras e dos fundamentos dos esportes, incluindo procedimentos de organização, sistematização de informações e aperfeiçoamento entre outros. Aos conteúdos conceituais de

${ }^{1} \mathrm{O}$ texto, ao tratar do termo corpo como elemento socioculturalmente construído, pretere a ideia de organismo no sentido fisiológico (p. 29).

Movimento, Porto Alegre, v. 15, n. 04, p. 107-126, outubro/dezembro de 2009. 
regras, táticas e alguns dados históricos factuais de modalidades, somam-se reflexões sobre os conceitos de ética, estética, desempenho, satisfação, eficiência, entre outros. E, finalmente, os conteúdos de natureza atitudinal são explicitados como objeto de ensino e aprendizagem e propostos como vivências concretas pelo aluno, o que viabiliza a construção de uma postura de responsabilidade perante si e o outro. (BRASIL, 1998, p. 82).

Conforme pontuara o Decreto 69.450/71 outrora, a Educação Física escolar objetivou o adestramento físico para a formação de um corpo produtivo, forte e saudável. Enfoque que influía na priorização de atividades físicas e desportivas, dada a responsabilidade pela descoberta de talentos para as competições. Tudo leva a crer que os conteúdos historicamente vinculados à área se limitavam ao saber fazer, ou seja, focavam unicamente nas dimensões procedimentais.

Em decorrência da proposição de conhecimentos conceituais e atitudinais conjuntamente aos procedimentais, apresentam-se novos elementos que subsidiam a transformação não somente do processo de ensino e aprendizagem como também dos conteúdos e, consequentemente, dos objetivos do componente. A análise dos PCNs revela a proposição de conhecimentos a serem ensinados e objetivos a serem alcançados que, até então, não figuravam das propostas existentes. Pode-se dizer que tal perspectiva enseja uma tendência à superação das ações didáticas que caracterizavam a Educação Física.

Essa observação corrobora as análises de Darido et al. (2001, p. 21):

Na prática concreta de aula significa que o aluno deve aprender a jogar queimada, futebol de casais ou basquetebol, mas, juntamente com estes conhecimentos, deve saber quais os benefícios de tais práticas, porque se praticam tais manifestações da cultura corporal hoje, quais as relações dessas atividades com a produção da mídia televisiva, impressa, dentre outras. Dessa forma, mais do que ensinar a fazer, o objetivo é que os alunos e alunas obtenham uma contextualização das informações como também aprendam a se relacionar com os colegas, reconhecendo quais valores estão por trás de tais.

Movimento, Porto Alegre, v. 15, n. 04, p. 107-126, outubro/dezembro de 2009. 


\section{Astigos Orifinais Lílian C. Gramorelli e Marcos G. Neira}

Ainda em relação aos conteúdos, os Parâmetros Curriculares Nacionais de Educação Física do $3^{\circ}$ e $4^{\circ}$ ciclos sugerem sua organização em "blocos", indiciando uma reconfiguração curricular dos saberes do componente.

Os conteúdos estão organizados em três blocos, que deverão ser desenvolvidos ao longo de todo o ensino fundamental. A distribuição e o desenvolvimento dos conteúdos estão relacionados com o projeto pedagógico de cada escola e a especificidade de cada grupo. A característica do trabalho deve contemplar os vários níveis de competência desenvolvidos, para que todos os alunos sejam incluídos e as diferenças individuais resultem em oportunidades para troca $\mathrm{e}$ enriquecimento do próprio trabalho. Dentro dessa perspectiva, o grau de aprofundamento dos conteúdos estará submetido às dinâmicas dos próprios grupos, evoluindo do mais simples e geral para o mais complexo e específico ao longo dos ciclos (BRASIL, 1998, p. 67-68).

Atendendo ao solicitado pelo artigo 26 da Lei de Diretrizes e Bases (9.394/1996), os blocos de conteúdos deverão articular-se ao projeto pedagógico da escola e às características dos alunos. Distribuídos em "Esportes, jogos, lutas e ginásticas", "Atividades rítmicas e expressivas" e "Conhecimentos sobre o corpo", foram arrolados conteúdos nas dimensões conceitual, procedimental e atitudinal que subsidiarão a organização das atividades de ensino.

A partir dos PCNs, portanto, o que se espera é que as aulas de Educação Física transcendam a atividade corporal e propiciem aos alunos diferentes aprendizagens. Destaque-se que dentre os conteúdos arrolados, despontam conhecimentos inexistentes nas propostas anteriores. Para além de diversos princípios, fatos, conceitos, normas, regras e valores relacionados aos esportes, jogos etc., convém ressaltar a composição do bloco denominado "Conhecimentos sobre o corpo".

Finalmente, a análise do documento permitiu identificar mais um aspecto que escapa à tradição da área: a concepção de avaliação da aprendizagem. Se considerarmos que o ensino da Educação Física, ao menos na liturgia oficial, preconizara conteúdos procedimentais comumente relacionados às capacidades físicas e habilidades esporti-

Movimento, Porto Alegre, v. 15, n. 04, p. 107-126, outubro/dezembro de 2009. 
vas (Decreto $n^{\circ}$ 69.450/71), é de se esperar que o formato da avaliação se mostrasse alinhado aos pressupostos biológicos e comportamentalistas, consubstanciados em baterias de testes para mensuração do desempenho ou, no limite, à verificação da execução de movimentos.

A concepção de avaliação decorrente foi marcada por um enfoque quantitativo, que estratificava os aptos e inaptos. Por conseguinte, a presença de testes físicos procurava medir e atribuir valores às capacidades físicas força, agilidade, equilíbrio e resistência. Não raro, a dificuldade de aferir avanços nesse terreno levava os professores a avaliar elementos pouco afeitos aos conhecimentos da Educação Física: a assiduidade às aulas, o uso de uniformes e a disciplina eram submetidos a um juízo de valor arbitrário e sem qualquer vínculo com os conteúdos de ensino, tal como denunciaram Mattos e Neira (2000, p. 23):

\begin{abstract}
A avaliação nas aulas de Educação Física tem buscado, freqüentemente, o atendimento às normas burocráticas da instituição e é atribuída, geralmente, levando-se em consideração a "presença" do aluno nas aulas, o uso de trajes adequados à prática e, quando muito, o resultado da execução de movimentos. Essa postura avaliativa indica a desconsideração da reflexão a respeito do papel que a avaliação assume enquanto elemento constitutivo de um projeto pedagógico. O professor termina por desvincular a ação pedagógica do seu processo de avaliação, preocupando-se mais com símbolo utilizado do que com a representação daquele índice em termos de aprendizagem do aluno. A idéia de medida, transmitida por essa concepção de avaliação, precisa ser, a todo custo, descaracterizada.
\end{abstract}

É interessante constatar que a ênfase nos aspectos quantitativos não era exclusividade da Educação Física. A avaliação tinha a função de medir o quanto os alunos se apropriaram dos conhecimentos, sendo assim, o foco priorizava a aquisição de conteúdos e não o processo de construção e desenvolvimento dos alunos. Como indicam Gimeno Sacristán e Pérez Gómez (1998, p. 300), a avaliação durante os anos 1960 e 1970 recorria predominantemente a técnicas objetivas: "A preocupação pela objetividade na medição de resultados educativos com a consequente proliferação dos testes, prestaram à educação 


\section{Artigos Orifinais Lilian C. Gramorelli e Marcos G. Neira}

parâmetros para julgar a avaliação e realizá-la com a intenção de que fosse uma tecnologia precisa".

A concepção de avaliação presente nos PCNs se distancia das antigas noções de seleção e classificação com base em critérios de habilidades físicas e esportivas que marcaram a Educação Física. Em consonância com os significados veiculados pela LDB 9.394/96, enfatiza os aspectos qualitativos sobre os quantitativos, alenta para a importância de uma perspectiva contínua e cumulativa e ratifica a proposta de um processo que oferecerá instrumentos valiosos para intervenção nas aprendizagens dos alunos.

A predominância das intenções avaliativas ocorrerá dentro de uma perspectiva processual, ou seja, facilitará a observação do aluno no processo de construção de conhecimento. Essa avaliação contínua compreende as fases que se convencionou denominar diagnóstica ou inicial, formativa ou concomitante e somativa ou final (BRASIL, 1998, p. 58).

A análise do documento deixa transparecer uma visão de avaliação integrada às demais esferas da ação educativa. Segundo consta, a fase denominada diagnóstica ou inicial fornecerá os dados para a elaboração de um projeto de desenvolvimento dos conteúdos, tendo em vista os conhecimentos prévios do aluno. Nos dizeres de Zabala (1998, p. 19), a avaliação é um processo cuja etapa inicial tem como função proporcionar "[...] referências para definir uma proposta hipotética de intervenção, ou seja, a organização de uma série de atividades de aprendizagem [...]", a fim de possibilitar o progresso dos alunos. Para Hadji (2001, p. 19), a avaliação diagnóstica ou inicial é denominada prognóstica

[...] na medida em que identifica certas características do aprendiz e faz um balanço, certamente mais ou menos aprofundado, de seus pontos fortes e fra$\cos$. A avaliação prognóstica tem a função de permitir um ajuste recíproco aprendiz/programa de estudos.

Com respeito à fase formativa, os PCNs sugerem a ocorrência concomitante da avaliação e do processo de ensino, tendo em vista o fornecimento de dados importantes para o ajuste das ações educativas,

Movimento, Porto Alegre, v. 15, n. 04, p. 107-126, outubro/dezembro de 2009. 
possibilitando a tomada de decisões quanto à continuidade do programado ou da necessidade de alteração (BRASIL, 1998). Ratificando essa ideia, Hadji (2001, p. 19) propõe que a avaliação formativa deva ocorrer "[...] no meio da ação educativa, ou seja, que ela possa contribuir para a regulação das atividades de ensino e favoreça um replanejamento das atividades". Na mesma linha de raciocínio, Zabala (1998, p. 200) aponta que a avaliação formativa, denominada por ele reguladora, deve possibilitar uma nova adequação dos planos e atividades conforme "as respostas dos meninos e meninas às nossas propostas".

A fase final ou somativa, conforme observado na proposta oficial, é uma maneira de avaliar as aprendizagens alcançadas. Essa perspectiva é ecoada por Hadji (2001, p. 19), quando denomina a avaliação final de cumulativa, atribuindo-lhe "[...] a função de verificar se as aquisições visadas pela formação foram feitas”, e por Zabala (1998, p. 200), para quem a avaliação final é aquela que se refere aos resultados obtidos e aos conhecimentos adquiridos, uma vez que se trata de:

[...] um informe global do processo que, a partir do conhecimento inicial (avaliação inicial) manifesta a trajetória seguida pelo aluno, as medidas específicas que foram tomadas, o resultado final de todo o processo e, especialmente, a partir deste conhecimento, as previsões sobre o que é necessário continuar fazendo ou o que é necessário fazer de novo.

Pelas considerações dos autores, percebe-se na proposta oficial a preocupação com a trajetória dos alunos em suas diferentes aprendizagens, consubstanciada numa visão de avaliação que possibilite o reconhecimento desse percurso, pela identificação dos conhecimentos inicialmente disponíveis e o quanto o grupo se apropriou dos conteúdos ensinados. A avaliação, conforme os PCNs, deve

[...] ser de utilidade, tanto para o aluno como para o professor, para que ambos possam dimensionar os avanços e as dificuldades dentro do processo de ensino e aprendizagem e torná-lo cada vez mais produtivo. (BRASIL, 1998, p. 58).

O que se espera é que o ato avaliativo subsidie o trabalho pedagógico, reoriente as situações didáticas de forma a promover o alcance dos

Movimento, Porto Alegre, v. 15, n. 04, p. 107-126, outubro/dezembro de 2009. 


\section{Artigos Orifinais Lilian C. Gramorelli e Marcos G. Neira}

objetivos desejados e forneça aos alunos informações sobre o andamento de suas aprendizagens.

Pelo exposto, entendemos que o documento remete a um novo olhar sobre a avaliação na Educação Física, o qual supera o caráter de seleção e estratificação dos mais aptos e passa a enfatizar a necessidade da utilização de outros recursos na intenção de informar os diversos sujeitos da ação didática acerca do processo de ensino e aprendizagem.

\section{OUVINDO OS PROFESSORES}

Seguindo as recomendações de Franco (2003), averiguamos por meio da análise documental que os PCNs contribuem significativamente para a reconfiguração didática da Educação Física ao defender o princípio da inclusão nas aulas, a organização de um currículo pautado nas dimensões dos conteúdos e a adoção da avaliação processual. Com base no método projetivo de Lankshear e Knobel (2008), esses indicadores, transformados em categorias a priori, inspiraram a elaboração de dispositivos para evocação junto a um grupo focal.

Os participantes do estudo responderam voluntariamente a um convite aberto dos pesquisadores, lançado em grupos de discussão de Educação Física escolar da Internet. Como critério único, bastava que atuassem nos anos finais do Ensino Fundamental. Após um curto período de troca de mensagens, o encontro foi realizado em um sábado, numa das salas de aula da Universidade. Participaram do estudo quatro professores de Educação Física da rede pública estadual paulista, três pertencentes a redes municipais e dois da rede privada, cujo tempo de magistério oscilava entre dois e treze anos.

Sem qualquer menção aos Parâmetros Curriculares Nacionais, os professores foram estimulados a comentar filmagens de aulas, relatos escritos de situações didáticas e registros avaliativos. Todos os dispositivos para evocação aludiram às categorias construídas com base na análise documental. Os depoimentos dos participantes, inicialmente gravados em vídeo, foram submetidos à interpretação crítica após a transcrição. Tais procedimentos de pesquisa permitiram coletar e analisar as impressões dos depoentes com referência a práticas pedagógicas convergentes com a proposta oficial.

Movimento, Porto Alegre, v. 15, n. 04, p. 107-126, outubro/dezembro de 2009. 
A interpretação dos comentários dos professores constatou o predomínio de posicionamentos favoráveis à perspectiva inclusiva expressa nas filmagens, inferida a partir da alusão aos cuidados com relação à seleção dos conteúdos. Nas suas palavras "em função do que se ensina, haverá inclusão ou exclusão dos alunos". ${ }^{2}$ Outro fato digno de nota diz respeito à noção de inclusão manifestada. Para os professores entrevistados, a inclusão implica em diferentes formas de participação dos alunos nas aulas, podendo dar-se por outros meios e não exclusivamente baseando-se nos pressupostos do movimentar-se fisicamente. Apresentaram como alternativas a realização de pesquisas, debates, análises de vídeos, imagens, textos, saídas pedagógicas, palestras, enfim, inúmeras atividades que revelam, em certa medida, uma visão diferenciada do ensino da Educação Física.

A partir de depoimentos tecidos sobre os dispositivos de evocação referentes a contextos de inclusão, foi evidenciada a noção de que todos os alunos têm direito a participar, ou seja, para os professores participantes do estudo, as atividades de ensino devem envolver a todos e as medidas adotadas para tal também poderão ser objeto de reflexão. Ainda com relação à inclusão, as manifestações dos docentes sugerem, por um lado, o abandono da ideia de desempenho atrelado à eficiência física e motora e, por outro, o respeito à individualidade dos alunos no decorrer das aulas.

Apesar de reconhecerem que a própria formação enfatizou a preocupação com as questões motoras, após o confronto com os materiais problematizadores, os depoimentos docentes revelam a necessidade das aulas de Educação Física propiciarem, também, aprendizagens de conteúdos conceituais, pois, segundo afirmou um participante, “[...] estes ampliam os conhecimento dos alunos numa perspectiva crítica".

Ao elencar os conteúdos conceituais, os PCNs recomendam a problematização de conceitos relacionados às manifestações da cultura corporal, quais sejam, suas informações históricas, origens e características. Após a assistência às filmagens em que esses conteúdos eram ensinados, os participantes, em tom de concordância, demonstraram

2 Transcrição da fala do Professor B.

${ }^{3}$ Transcrição da fala do Professor C.

Movimento, Porto Alegre, v. 15, n. 04, p. 107-126, outubro/dezembro de 2009. 
preocupações com "ir além das práticas corporais", o que nos permite inferir que, ao menos nas escolas onde atuam esses professores, os currículos da Educação Física vêm sofrendo transformações no que diz respeito aos conteúdos abordados, alinhando-se às intenções oficiais.

Outra nuance que emergiu das discussões foi a percepção dos professores com relação ao ensino dos conteúdos atitudinais. Segundo os participantes do grupo focal, as atitudes devem permear o debate nas aulas, seja nas análises sobre as ações realizadas do tema em estudo, seja nas próprias ações dos alunos durante as atividades de ensino. Nota-se aqui, certo afastamento do proposto nos PCNs. Muito embora tenham ressaltado a importância do ensino de conteúdos atitudinais, para os participantes a visão demonstrada concebe as atitude simplesmente como elementos norteadores dos comportamentos dos alunos, e não como conhecimentos relacionados às manifestações da cultura corporal.

A análise do material recolhido revelou que alguns depoentes compreendem o ensino das atitudes como produto da reflexão sobre um acontecimento desagradável durante a aula, mesmo não relacionado com o objeto de estudo. Conforme as percepções veiculadas, para que sejam aprendidas, as atitudes "adequadas" devem ser explicadas. É necessário dizer que tal noção não encontra respaldo nas teorias que fundamentam a concepção de aprendizagem presente no texto oficial. Conforme Pozo (2000), enquanto os conteúdos conceituais (fatos, princípios e conceitos) requerem experiências expositivas e reflexivas, os conteúdos atitudinais (regras, normas e valores), segundo Sarabia (2000), solicitam a repetição de vivências e modelos. Obviamente, a reflexão sobre os acontecimentos é relevante, mas, para que a aprendizagem atitudinal se dê a contento, não basta pensar sobre, é necessário atuar a partir dela.

No que tange às percepções acerca do ensino dos conhecimentos sobre corpo, a análise dos depoimentos constatou divergências. Enquanto alguns participantes silenciaram com relação às imagens onde eram ensinados conteúdos pertencentes a esse bloco, outros se manifestaram favoravelmente ao tratamento de temáticas como a alimentação e conceitos referentes à prática de atividade física, tendo

Movimento, Porto Alegre, v. 15, n. 04, p. 107-126, outubro/dezembro de 2009. 
em vista a possibilidade de esses conteúdos auxiliarem os alunos na tomada de decisões em prol de uma melhor qualidade de vida. Houve ainda um professor que explicitou sua total discordância, pois, no seu entendimento, o bloco "conhecimentos sobre o corpo" enfatiza uma visão de atividade física alinhada à cultura hegemônica, o que não coaduna com o papel transformador da educação.

$\mathrm{O}$ debate em torno das imagens que aludiram ao ensino dos conhecimentos sobre o corpo, como se nota, gerou divergência entre os participantes do grupo focal. Se, por um lado, os posicionamentos em defesa desses conteúdos indicam percepções favoráveis aos PCNs, o silêncio verificado talvez sinalize discordâncias com respeito à característica das aulas que assistiram e dos registros avaliativos que leram. Afinal, nas imagens empregadas como dispositivo de evocação, o professor em tela expunha oralmente alguns conceitos relativos ao funcionamento do sistema cardiovascular e sua relação com a atividade física. Sem desconsiderar a característica do material empregado para provocar a discussão, convém afirmar que a maioria dos depoimentos não denotou simpatia com situações didáticas centradas nos conhecimentos biológicos e fisiológicos.

No tocante à terceira categoria eleita a partir da análise dos PCNs, a avaliação, sua problematização junto ao grupo focal evidenciou algumas percepções bem interessantes. Os professores participantes consideram a avaliação uma etapa fundamental do processo de ensino e aprendizagem. Compreensão que se distancia do caráter tecnicista que vigorou nas propostas anteriores quando propunham a utilização de testes para mensuração e classificação dos alunos.

Os posicionamentos dos participantes do estudo indicam que a avaliação acontece em diferentes momentos do cotidiano, sem que seja necessária uma data previamente estipulada, bem como utilizam vários instrumentos avaliativos. Os informantes também mencionaram que a avaliação subsidia o replanejar das ações didáticas: "avaliar não significa olhar apenas para o que o aluno já sabe, mas, também, olhar para a própria prática pedagógica". ${ }^{4}$

\footnotetext{
${ }^{4}$ Transcrição da fala do professor D.

Movimento, Porto Alegre, v. 15, n. 04, p. 107-126, outubro/dezembro de 2009.
} 


\section{Astifor Orifinais Lílian C. Gramorelli e Marcos G. Neira}

As colocações dão-nos indícios que os professores do grupo focal sintonizam com a concepção de avaliação presente nos PCNs de Educação Física. Os depoentes percebem a necessidade de se avaliar o processo, reconhecer as maneiras distintas com que os alunos participam das aulas e a validade do uso de diferentes instrumentos. Mesmo que não tenham se referido às fases diagnóstica, reguladora e final, amplamente debatidas no documento, suas percepções no tocante à avaliação rompem com a tradição da área.

\section{Algumas CONSIDERAÇões}

Passados dez anos da publicação dos Parâmetros Curriculares Nacionais de Educação Física $-3^{\circ}$ e $4^{\circ}$ Ciclos, é possível apontar algumas transformações, ao menos na concepção que os professores possuem sobre o ensino da Educação Física na escola. Em certa medida, é lícito afirmar que as percepções docentes se aproximam dos pressupostos presentes na proposta curricular oficial.

As referências aos objetivos da Educação Física evidenciaram preocupações com uma formação que extrapole as posturas anteriores exclusivamente centradas no desenvolvimento dos aspectos físicos e motores. Destacam-se, também, as alusões à importância de incluir a todos os alunos nas aulas, ao ensino de conteúdos conceituais e ao papel pedagógico das ações avaliativas.

Quando comparadas às concepções de Educação Física anteriores aos PCNs, as percepções demonstradas pelos professores que participaram da investigação indicam a emergência de um posicionamento renovado com relação ao currículo do componente. Embora se coadunem com as proposições oficiais, vale ressaltar a inviabilidade de interpretar as noções percebidas como exclusivamente fundamentadas no documento. Entendemos que a proliferação do discurso pedagógico contido nos PCNs por meio de publicações editoriais diversas, cursos de formação inicial e contínua, bem como a emergência de políticas públicas oriundas dos sistemas de ensino, vêm contribuindo para sedimentação das noções aqui desveladas. Assim sendo, se por um lado as descobertas da investigação não permitem afirmar que as percepções docentes se transformaram em função da publicação dos

Movimento, Porto Alegre, v. 15, n. 04, p. 107-126, outubro/dezembro de 2009. 
PCNs, por outro é bastante viável a ideia de que a pulverização e ampla socialização desse mesmo discurso pedagógico, de algum modo, alcançou determinados professores de Educação Física que atuam no Ensino Fundamental.

Para finalizar, retomemos a epígrafe de José Saramago. Digamos ao rei que no decorrer desta navegação pudemos encontrar ilhas desconhecidas que estavam no mapa. Afinal, quando instigados ao debate, os docentes veicularam percepções que dão pistas de uma prática educativa da Educação Física influenciada por novos ideais e significados, o que lhes propicia superar os paradigmas que marcaram antigas propostas. Convém, portanto, lançar um alerta a todos os navegantes. Para que sejam descobertas e exploradas as ilhas que, mesmo no mapa, ainda estão por conhecer, as ações deverão ser conduzidas por timoneiros cujas experiências encontrem amparo em cartas bem elaboradas. 


\section{Astigos Originais Lílian C. Gramorelli e Marcos G. Neira}

Ten years of national curricular parameters:
Physical Education practice according to the
authors
ABSTRACT: The study checked possible theory-
methodologic assumptions into Physical Education PCNs
by the teachers of the last years of elementary school.
The analyses in the publishing allow us to identify the
different didactic procedures when compared with those
which set up the traditional expectations. From these
elements and using the projective method, it was
developed an interview with focal group. The data
obtained showed us docent perceptions which re-
arrange the educative practice, and interpretation allows
us to realize which of the teachers views approaches
the propositions in the official document, even if no
reference has been done to it.
Keywords: Physical Education. Education, primary. Cur-
riculum. Learning.

Diez años de parámetros curriculares nacionales: la práctica de la Educación Física en la visión de sus actores

Resumen: El estudio ha averiguado apropiaciones posibles de las propuestas teórico-metodológicas pertenecientes a los PCNs de la Educación Física por los profesores que actúan en los años finales de la Enseñanza Elementar. La análisis de la publicación nos ha permitido identificar direcciones didácticas diferenciadas con respecto a las que componían tradicionalmente el área. Con estos elementos y al recurrir al método proyectivo, se ha desarrollado una entrevista en un grupo seleccionado. Los datos apuntados nos dirigen hacia la percepción de los docentes que rehacen la práctica y su interpretación nos ha permitido identificar que las concepciones de los profesores se acercan a las proposiciones oficiales, aunque a él no se haya sido hecha ninguna alusión.

Palabras clave: Educación Física. Educación primaria. Curriculum. Aprendizage.

\section{REFERÊNCIAS}

BRASIL. Presidência da República. Decreto n 69.450 de $1^{\circ}$ de novembro de 1971. In: SÃO PAULO (Estado). Secretaria Estadual de Educação. Coordenadoria de

Movimento, Porto Alegre, v. 15, n. 04, p. 107-126, outubro/dezembro de 2009. 
Dez anos de parâmetros curriculares nacionais: a prática...

Estudos e Normas Pedagógicas. Educação Física: legislação básica. São Paulo: SEE/CENP, 1985.

. Lei de Diretrizes e Bases da Educação Nacional n 9.394/96. Diário Oficial da União. Brasília, 20 de dezembro de 1996.

. Ministério da Educação e Desporto. Secretaria da Educação Fundamental. Parâmetros Curriculares Nacionais: Terceiro e Quarto Ciclos do Ensino Fundamental - Educação Física. Brasília: MEC/SEF, 1998.

CAPARROZ, Francisco Eduardo. Parâmetros Curriculares Nacionais de Educação Física: "O que não pode ser que não é o que não pode ser que não é". In: BRACHT, Valter; CRISÓRIO, Ricardo. (Org.) A Educação Física no Brasil e na Argentina: identidade, desafios e perspectivas. Campinas: Autores Associados, 2003.

DARIDO. Suraya Cristina et al. A Educação Física, a formação do cidadão e os parâmetros curriculares nacionais. Revista Paulista de Educação Física, São Paulo, v. 11, n. 1, p.17-32, jan./jun. 2001.

FRANCO, Maria Laura Puglisi Barbosa. Análise de conteúdo. Brasília: Plano, 2003.

GIMENO SACRISTÁN, José.; PEREZ GÓMEZ, Ángel Ignacio. Compreender e transformar o ensino. Porto Alegre: Artmed, 1998.

HADJI, Charles. Avaliação desmistificada. Porto Alegre: Artmed, 2001.

LANKSHEAR, Colin; KNOBEL, Michele. Pesquisa pedagógica: do projeto à implementação. Porto Alegre: Artmed, 2008.

LIMA, Maria Emília de; GRAMORELLI, Lílian Cristina. Política, economia e sociedade: reflexos sobre o projeto educativo da Educação Física. In: NEIRA, Marcos Garcia. Ensino de Educação Física. São Paulo: Thomson Learning, 2007. p.31-62.

MATTOS, Mauro Gomes de; NEIRA, Marcos Garcia. Educação Física na adolescência: construindo o movimento na escola. São Paulo: Phorte, 2000.

NEIRA, Marcos Garcia; NUNES, Mário Luiz Ferrari. Pedagogia da cultura corporal: crítica e alternativas. São Paulo: Phorte, 2006.

POZO, Juan Ignacio. A aprendizagem e o ensino de fatos e conceitos. In: COLL, Cesar et al. Os conteúdos na reforma: ensino e aprendizagem de conceitos, atitudes e procedimentos. Porto Alegre: Artmed, 2000.

RODRIGUES, Alberto Tosi. Gênese e sentido dos parâmetros curriculares nacionais e seus desdobramentos para a Educação Física escolar brasileira. Revista Brasileira de Ciências do Esporte, Campinas, v. 23, n. 2. p.135-147, jan., 2002.

SARABIA, Bernabé. A aprendizagem e o ensino das atitudes. In: COLL, Cesar et al. Os conteúdos na reforma: ensino e aprendizagem de conceitos, atitudes e procedimentos. Porto Alegre: Artmed, 2000.

Movimento, Porto Alegre, v. 15, n. 04, p. 107-126, outubro/dezembro de 2009. 


\section{Artigos Orifinais Lilian C. Gramorelli e Marcos G. Neira}

SARAMAGO, José. 0 conto da ilha desconhecida. São Paulo: Companhia das Letras, 1998.

ZABALA, Antoni. A prática educativa. Porto Alegre: Artmed, 1998.

Recebido em: 18.11 .2008

Aprovado em: 08.05.2009

Novimento, Porto Alegre, v. 15, n. 04, p. 107-126, outubro/dezembro de 2009. 